Tema: Aciaria Oxigênio

\title{
DESSULFURAÇÃO DE GUSA LÍQUIDO UTILIZANDO AGENTE DESSULFURANTE À BASE DE CARBURETO DE CÁLCIO E MAGNÉSIO METÁLICO*
}

\author{
José Flávio Viana ${ }^{1}$ \\ José Edison Ferreira Coelho Filho ${ }^{2}$ \\ Alan Jardim Nascimento ${ }^{3}$
}

\begin{abstract}
Resumo
A dessulfuração do gusa líquido tem papel fundamental na obtenção de baixos teores de enxofre no aço, considerando que o processo de refino primário envolve utilização de oxigênio, prejudicando a dessulfuração nesta etapa. A busca de processos cada vez mais eficientes levou ao desenvolvimento da dessulfuração do gusa com a utilização simultânea de agente dessulfurante à base de carbureto de cálcio junto com o magnésio metálico em co-injeção ou multi-injeção. Este trabalho tem objetivo de mostrar os resultados desta aplicação em panelas de gusa líquido na ThyssenKrup CSA Siderúrgica do Atlântico, Rio de Janeiro, onde foi possível determinar ganhos de produtividade e custo.

Palavras-chaves: Carbureto de cálcio; Dessulfuração e Magnésio.

\section{HOT METAL DESULFURIZATION USING CALCIUM CARBIDE AND METALIC MAGENESIUM DESULFURIZATION AGENTES}

\begin{abstract}
The primary refining uses oxygen that prevents the hot metal from desulphurization. Therefore, the hot metal desulphurization is an essentiality for the production of low sulfur steel grades. The search for improvements of the desulphurization process lead to the use of desulphurization agents based on calcium carbide associated with metallic magnesium in co-injection or multi-injection. This paper describes the results of this kind of desulphurization in the hot metal ladle at ThyssenKrup CSA Siderúrgica do Atlântico, Rio de Janeiro, Brazil, where it was possible to show the benefits in productivity and cost.
\end{abstract}

Keywords: Calcium carbide; Desulphurization and magnesium

1 Engenheiro Metalurgista, Msc, CQE, CQA, Gerente de Processos, Tecnosulfur S/A, Membro da ABM, Sete Lagoas, MG, Brasil.

2 Técnico Metalurgista, Supervisor de Produção - Aciaria, ThyssenKrup CSA Siderúrgica do Atlântico, Rio de Janeiro, RJ, Brasil.

3 Técnico em Química e Metalurgia, Técnico em Química e Metalurgia, Assistente Técnico, Tecnosulfur S/A, Membro da ABM, Sete Lagoas, MG, Brasil.

* Contribuição técnica ao $45^{\circ}$ Seminário de Aciaria - Internacional, 25 a 28 de maio de 2014, Porto Alegre, RS, Brasil. 


\section{INTRODUÇÃO}

Devido à crescente demanda de aços com baixos teores de enxofre e considerando a dificuldade de dessulfuração no refino primário, a dessulfuração de gusa líquido representa uma etapa essencial no processo de aciaria.

Hüsken [1] apresentou um histórico das mudanças das especificações de aços, relativamente aos teores de enxofre visados correlacionados com os valores de resistência ao choque, nos últimos 50 anos, conforme Figura 1.

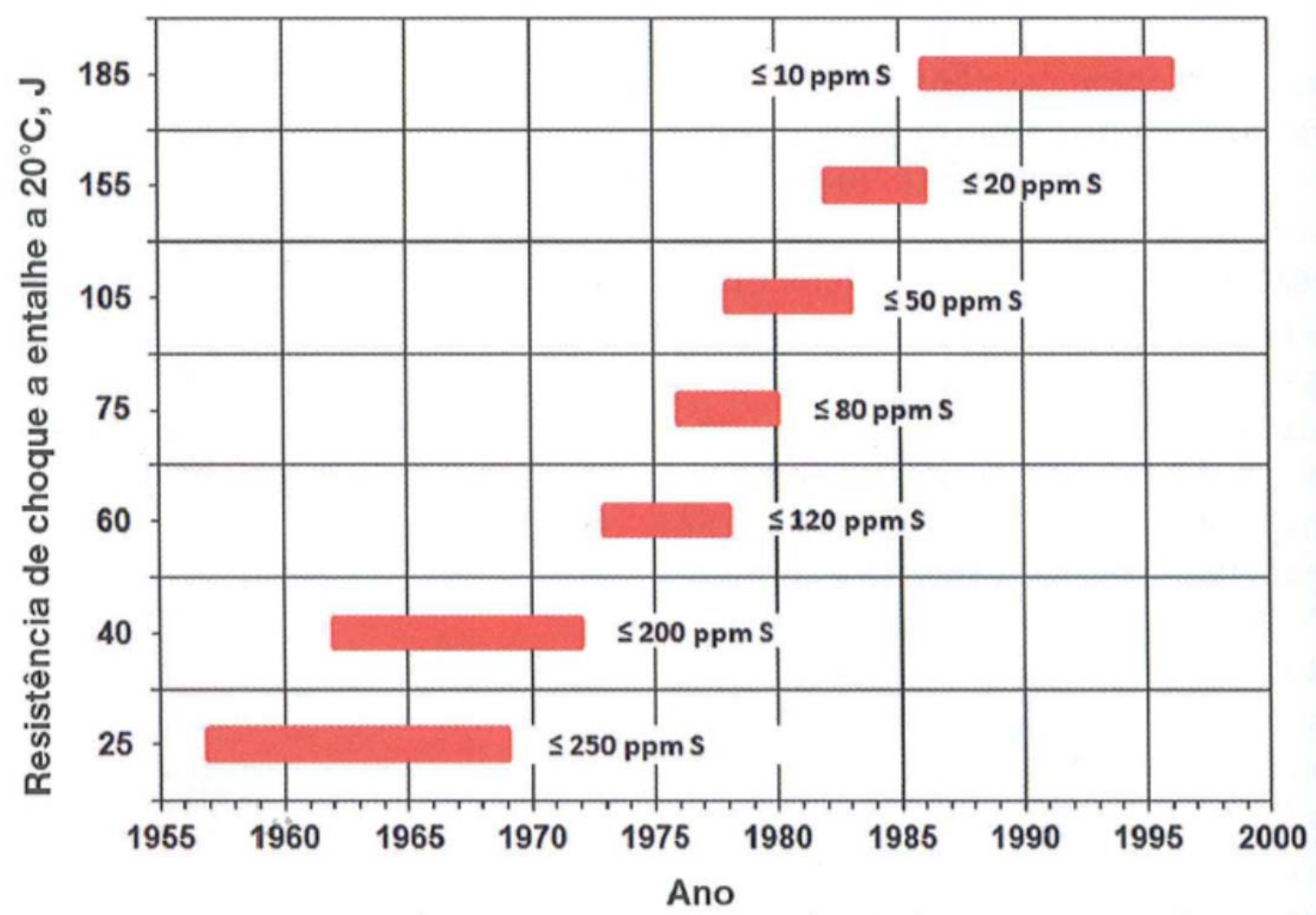

Figura 1. Requisitos de teores de enxofre dos aços e resistência ao choque [1].

Além da exigência de teores de enxofre mais baixos, Hüsken [1] também observa que se verifica atualmente um aumento de preço das matérias primas, como carvão, coque, minério de ferro ou sucata mais nobre, o que leva à utilização de matérias primas mais econômicas com maiores teores de enxofre.

A dessulfuração do gusa líquido é normalmente realizada através da injeção de agentes dessulfurantes à base de óxidos ou carbureto de cálcio (carbeto de cálcio) por lança refratária. Esta operação pode ser realizada na panela ou em carros torpedo, sendo que em carros torpedo observa-se um incremento do teor de enxofre quando o gusa líquido é vertido para a panela de carregamento. Isto ocorre devido à heterogeneidade do metal, causada pela forma do carro torpedo. Nadif, et al. [2] registrou incrementos de até $10 \mathrm{ppm}$ de enxofre no gusa líquido entre carro torpedo e panela. Entretanto, estes valores podem chegar até $40 \mathrm{ppm}$, dependendo do processo de injeção.

Para dessulfuração do gusa líquido, utiliza-se também desoxidantes metálicos como alumínio ou magnésio, que segundo Costa [3] favorecem a dissociação do $\mathrm{Ca}$ presente no óxido ou no carbureto para a reação com o S formando CaS. Segundo Cardoso Filho [4], a utilização do carbureto de cálcio como dessulfurante tem o custo

* Contribuição técnica ao $45^{\circ}$ Seminário de Aciaria - Internacional, 25 a 28 de maio de 2014, Porto Alegre, RS, Brasil. 
total de dessulfuração reduzido com o aumento do teor de magnésio metálico na mistura dessulfurante. Neste referido trabalho foram comparados os custos de dessulfuração para o agente dessulfurante injetado sem magnésio e com $13 \%$ e 18\%. A redução de custos obtida com maiores teores de magnésio metálico estimulou a busca de resultados ainda mais representativos em termos de custo, e consequentes tempos de tratamentos menores, realizando experimentos com maiores proporções de $\mathrm{Mg}$ na mistura.

A ThyssenKrupp CSA Siderúrgica do Atlântico possui uma estação de dessulfuração de gusa líquido em panelas com sistema de multi-injeção e utiliza rotineiramente carbureto de cálcio, cal e magnésio metálico no processo de dessulfuração de gusa. Em parceria com a Tecnosulfur S/A, foram realizados testes de co-injeção de agente dessulfurante à base de carbureto de cálcio e magnésio metálico na proporção de variando entre 15\% e 23\% para avaliação do potencial de redução de custos.

\section{MATERIAIS E MÉTODOS}

A Figura 2 mostra esquematicamente o sistema de multi-injeção da TKCSA, composto de 3 silos para os agentes dessulfurantes, 3 vasos de injeção e lança refratária para injeção em panelas com capacidade de 380 toneladas de gusa líquido.

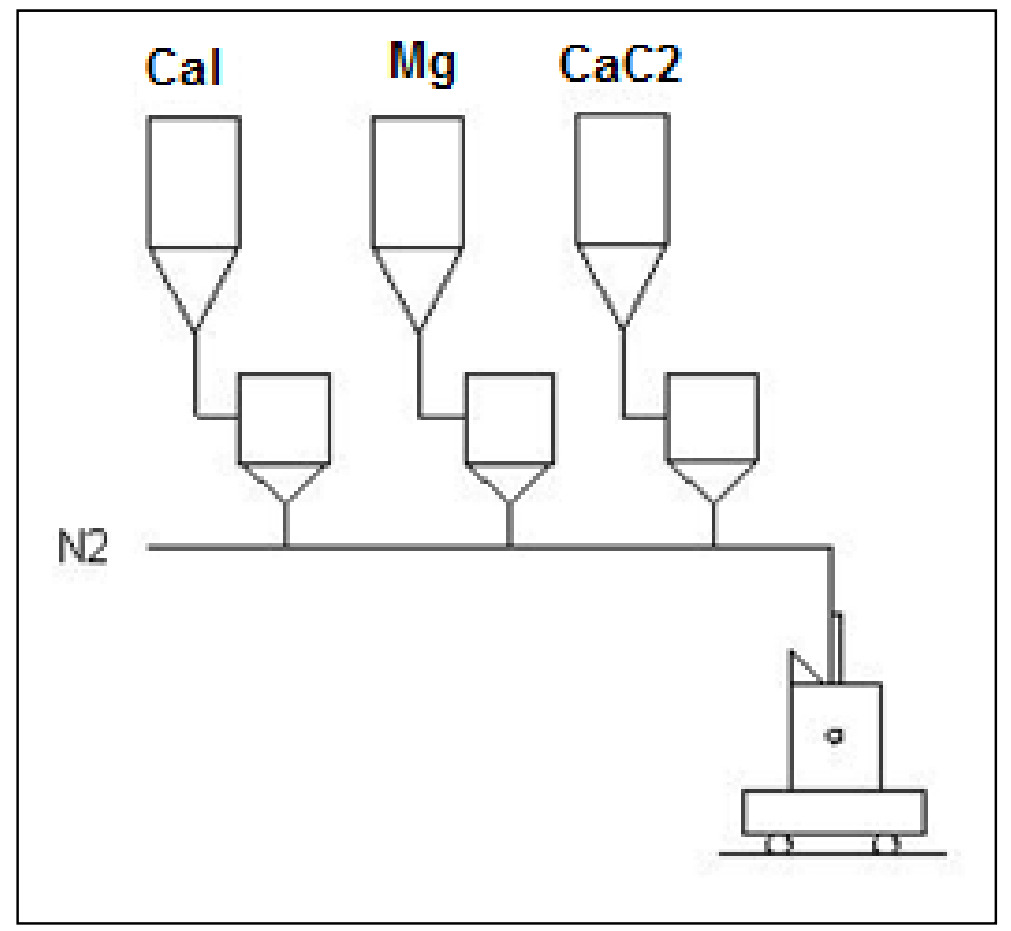

Figura 2. Fluxo esquemático da estação de dessulfuração da TKCSA.

* Contribuição técnica ao 450 Seminário de Aciaria - Internacional, 25 a 28 de maio de 2014, 
Para o experimento de co-injeção, o carbureto de cálcio foi substituído pelo agente dessulfurante à base de carbureto, cuja composição é apresentada na Tabela 1 e o magnésio metálico utilizado foi o mesmo do sistema de multi-injeção.

Tabela 1. Composição do agente dessulfurante TECDES 8094 utilizado na co-injeção

\begin{tabular}{|c|c|c|}
\hline Composto & $\mathrm{CaC}_{2}$ & $\mathrm{CaO}$ \\
\hline Proporção (\%) & $>48$ & 11 a 40 \\
\hline
\end{tabular}

No processo de co-injeção, o agente dessulfurante foi injetado durante todo o período de sopro de nitrogênio e o magnésio metálico a parir de 30 segundos de injeção até o final do tratamento. Foram utilizadas 27 toneladas de agente dessulfurante.

Para comparação de resultados de co-injeção do agente dessulfurante foi utilizado o resultado de co-injecão de cal e magnésio metálico em experimento realizado pela TKCSA em janeiro/13. Nesta oportunidade foi utilizada uma proporção média de $\mathrm{Mg}$ de $19 \%$.

\section{RESULTADOS}

A eficiência do processo de dessulfuração pode ser avaliada através dos aspectos cinéticos do processo, considerando que a equação cinética é de primeira ordem (equação 1).

$$
\text { - dS/dt = k (S-Seq) }
$$

Integrando a equação 1 , chega-se a equação 2 que pode ser aplicada ao processo de dessulfuração.

Onde:

$$
\mathrm{S}=\mathrm{S}_{0} \mathrm{e}^{-\mathrm{kt}}
$$

$\mathrm{S}=$ teor de enxofre no tempo "t";

$\mathrm{S}_{0}=$ teor de enxofre inicial;

$\mathrm{K}=$ coeficiente de transferência de massa global do processo de dessulfuração;

$\mathrm{t}=$ tempo de tratamento de dessulfuração.

A partir da equação 2 e considerando a taxa de dessulfuração constante, o consumo de magnésio pode ser calculado em função do $\ln \left(\mathrm{S}_{0} / \mathrm{S}\right)$, conforme equação 3.

Onde:

$$
\text { Consumo de } \mathrm{Mg}(\mathrm{kg} / \mathrm{ton})=\mathrm{k}^{*} \ln \left(\mathrm{S}_{0} / \mathrm{S}\right)
$$

$\mathrm{k}^{*}=$ constante para cálculo do consumo de $\mathrm{Mg}$.

Para efeito de avaliação da influência da proporção de magnésio metálico na mistura injetada sobre a eficiência de dessulfuração, estas variáveis foram correlacionadas conforme apresentado na Figura 3. Segundo Viana, et al. [5], a constante cinética é influenciada por diversos fatores operacionais como as taxas de injeção de agentes e dimensões da panela. Para evitar a influência da taxa de injeção da agente dessulfurante nos resultados foram selecionadas as corridas do teste com esta variável entre $7 \mathrm{~kg} / \mathrm{min}$ e $12 \mathrm{~kg} / \mathrm{min}$.

* Contribuição técnica ao $45^{\circ}$ Seminário de Aciaria - Internacional, 25 a 28 de maio de 2014, 

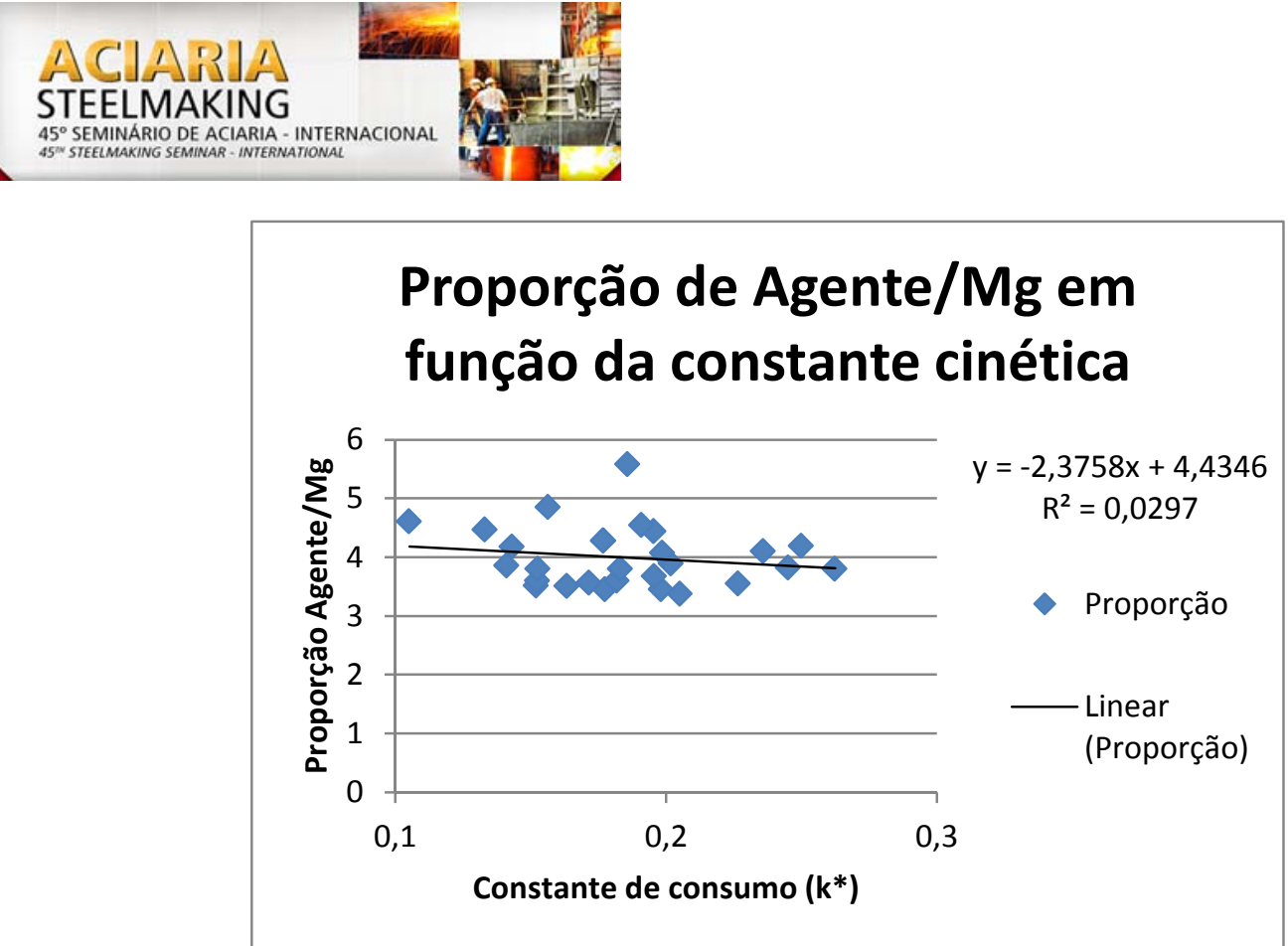

Figura 3. Resultados do teste de dessulfuração de Agente dessulfurante na TKCSA.

A correlação entre o $\ln (\mathrm{Si} / \mathrm{Sf})$ e o consumo de $\mathrm{Mg}$ observada no teste de co-injeção do agente dessulfurante é apresentada na Figura 4.

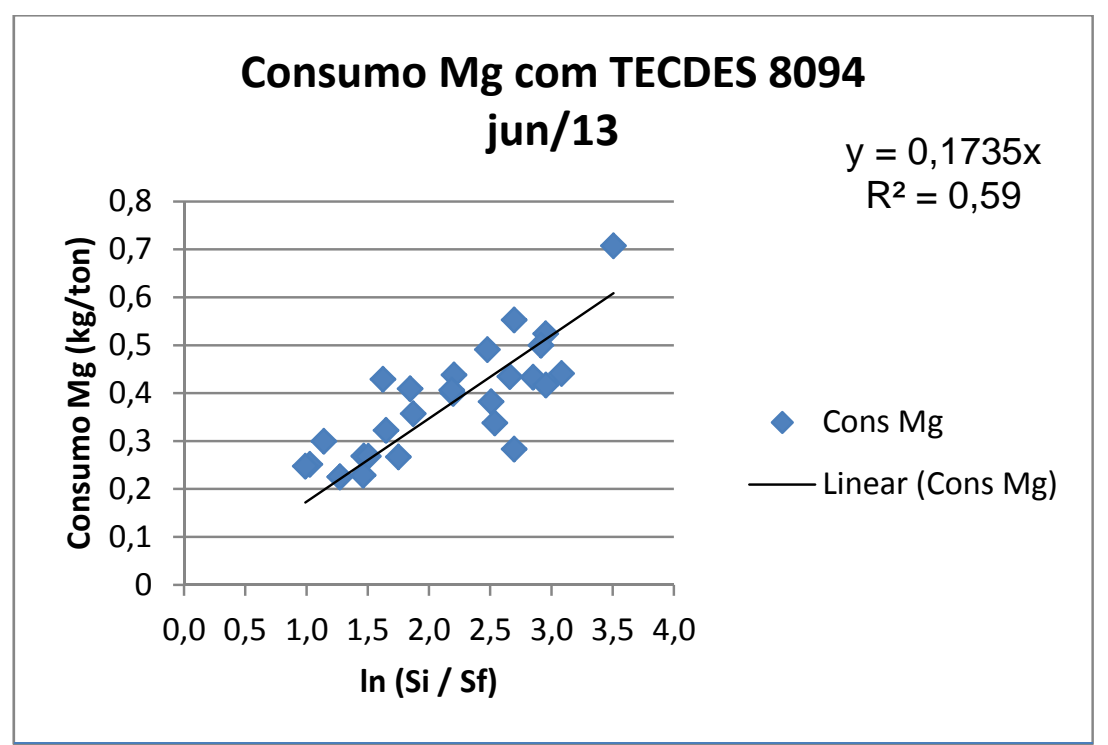

Figura 4. Resultados de testes de dessulfuração com agente dessulfurante na TKCSA.

A Figura 5 apresenta o resultado da co-injeção de cal e magnésio metálico na estação de dessulfuração da TKCSA.

* Contribuição técnica ao $45^{\circ}$ Seminário de Aciaria - Internacional, 25 a 28 de maio de 2014, Porto Alegre, RS, Brasil. 

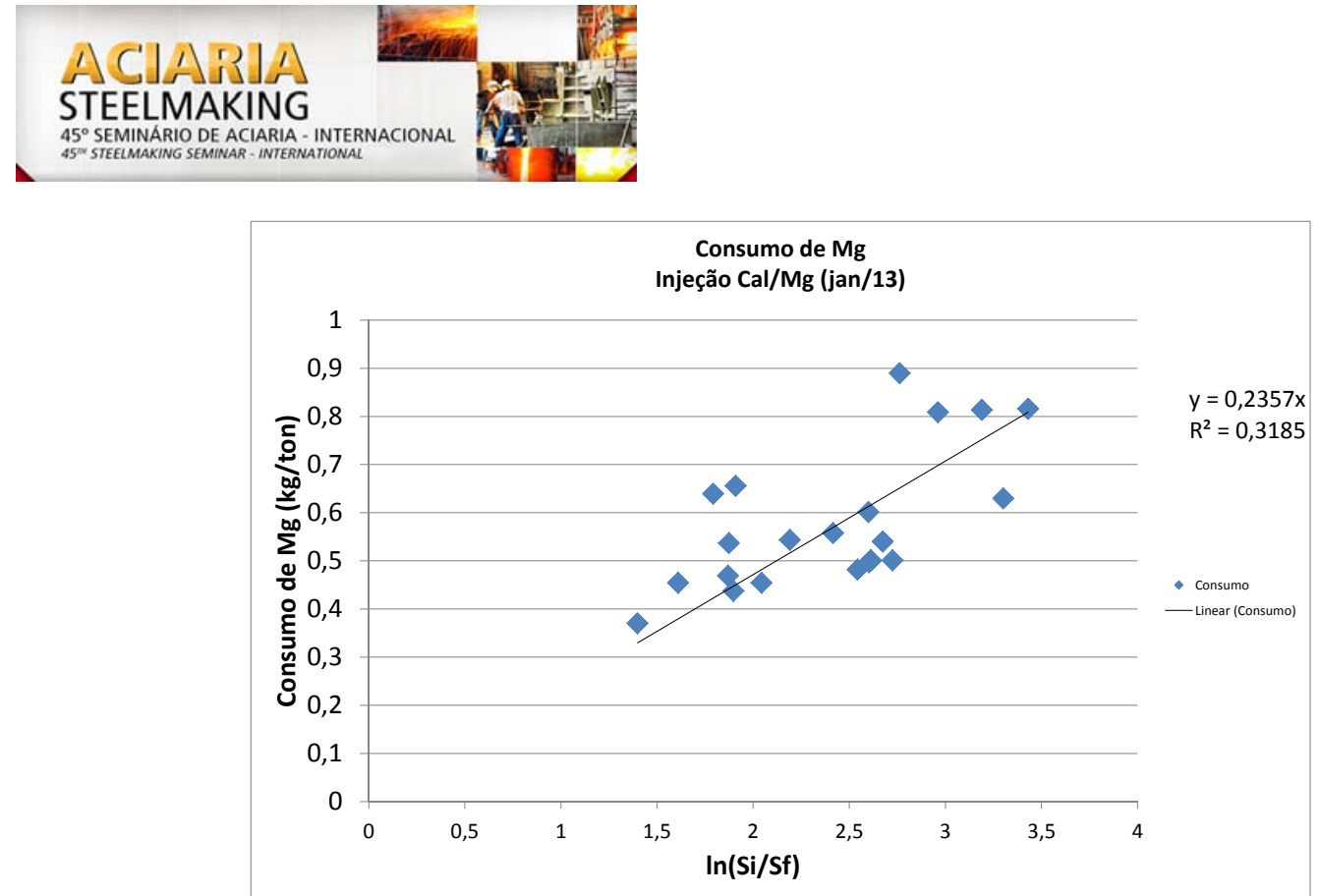

Figura 5. Resultados da co-injeção de cal e Mg na TKCSA>.

\section{DISCUSSÃO}

A comparação dos resultados apresentados nas Figuras 4 e 5 mostram as seguintes diferenças entre os processos de co-injeção de agente dessulfurante à base de carbureto de cálcio e de cal com magnésio metálico.

- A dispersão dos resultados de cal e Mg foram maiores, comparada à dispersão obtida na co-injeção de agente e Mg;

- O consumo de Mg foi maior na co-injeção com cal.

Na Figura 3 pode-se notar uma tendência de elevação do consumo de magnésio metálico à medida que é aumentada sua participação na mistura co-injetada. O coeficiente de correlação foi muito baixo para afirmar com certeza este resultado. Entretanto ele está em sentido oposto ao resultado observado por Cardoso Filho, et al. [4] nos testes realizados, onde a elevação da proporção de magnésio na mistura co-injetada melhorou a eficiência da dessulfuração com a redução da constante de consumo de $\mathrm{Mg}$.

A partir destes dados foi possível fazer uma comparação econômica dos dois processos considerando os preços de agentes dessulfurantes de mercado. Para as mesmas condições de teores de enxofre final e inicial, pode-se notar que o custo da dessulfuração foi reduzido em $23 \%$ utilizando o agente dessulfurante à base de carbureto de cálcio. Apesar do custo mais elevado do agente dessulfurante à base de carbureto o consumo de $\mathrm{Mg}$ é menor, além da redução da dispersão permitir a utilização de menor quantidade de dessulfurante para garantir o teor de enxofre visado.

Utilizando as correlações mostradas nas Figuras 4 e 5 , entre o $\ln \left(\mathrm{S}_{0} / \mathrm{S}\right)$ e o consumo de magnésio metálico, foi possível simular a quantidade de agentes dessulfurantes utilizados para reduzir o teor de enxofre do gusa líquido de 350ppm para 40ppm, apresentado na Tabela 2.

* Contribuição técnica ao 45 Seminário de Aciaria - Internacional, 25 a 28 de maio de 2014, 


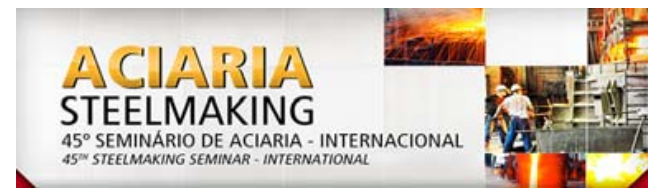

Tabela 2. Simulação do consumo de agentes dessulfurantes

\begin{tabular}{|c|c|c|c|c|}
\hline $\begin{array}{c}\text { Tipo de } \\
\text { dessulfuração }\end{array}$ & $\begin{array}{c}\text { Agente à base } \\
\text { de } \mathrm{CaC}_{2}(\mathrm{~kg})\end{array}$ & Cal $(\mathrm{kg})$ & $\begin{array}{c}\text { Magnésio } \\
\text { metálico }(\mathrm{kg})\end{array}$ & Total $(\mathrm{kg})$ \\
\hline Agente/Mg & 422 & & 117 & 539 \\
\hline Cal/Mg & & 973 & 220 & 1193 \\
\hline
\end{tabular}

Pode-se perceber pela Tabela 2, que o volume de escória gerado é $120 \%$ maior, com a utilização da dessulfuração com cal e Mg. Segundo estudos de Hüsken [1], $25 \%$ dos custos da dessulfuração de gusa são devidos às perdas metálicas durante o processo de escumagem, antes do carregamento. Logo, a utilização do agente dessulfurante à base de carbureto de cálcio em co-injeção com magnésio metálico traz como benefício extra a melhoria do rendimento metálico.

\section{CONCLUSÕES}

A co-injeção de agente dessulfurante à base de carbureto de cálcio com magnésio metálico possibilita a redução dos custos de dessulfuração em $23 \%$, devido aos agentes dessulfurantes, além de reduzir as perdas metálicas, graças à geração de um menor volume de escória.

$\mathrm{O}$ teste de 27 toneladas realizado na TKCSA mostrou que a combinação $\mathrm{CaC}_{2} / \mathrm{Mg}$ deve ser investigada em um período maior de tempo e assim consolidar a economia verificada com os agentes e as perdas metálicas, além de possibilitar determinar, com maior grau de confiabilidade, a influência da proporção de magnésio metálico na eficiência da dessulfuração.

\section{REFERÊNCIAS}

1 Hüsken R. Estratégias de dessulfuração na fabricação de aço com oxigênio. In: MPT Edição Brasileira. 2012;2:24-32.

2 Nadif M, Suero, J.; Salvadori, D.; Schadow, F.; Schutz, R., Perrin E, et al. Desulfurization in ArcelorMittal flat carbon Western Europe. Revie de Metallurgie. 2009;106(7-8):270-79.

3 Costa SL, Viana JF, Prenazi A. Dessulfuração de gusa em panela via injeção de CaOMg na Aciaria 2 da Usiminas. In: $30^{\circ}$ Seminário sobre Fusão, Refino E Solidificação dos Metais; maio 1999; Belo Horizonte, Brasil. São Paulo: ABM; 1999.

4 Cardoso Filho ACP, Araujo TCS, Alves HÁ, Viana JF. Avaliação do potencial de uso de agente dessulfurante à base de carbureto de cálcio em co-injeção com magnésio metálico na Usiminas. In: $41^{\circ}$ Seminário de Aciaria - Internacional; maio 2010; Resende, Brasil. São Paulo: ABM; 2010.

5 Viana JF, Costa SLS, Oliveira LJS. analysis of hot metal desulphurization process. In: Almamet Seminar; 2008; Lisboa, Portugal. Almamet; 2008.

* Contribuição técnica ao $45^{\circ}$ Seminário de Aciaria - Internacional, 25 a 28 de maio de 2014, 